\title{
Evidence for low high-density lipoprotein cholesterol levels in Australian indigenous peoples: a systematic review
}

\author{
Jasmine G Lyons ${ }^{1,2,4^{*}}$, Kerin O'Dea ${ }^{3,4}$ and Karen Z Walker ${ }^{1,5}$
}

\begin{abstract}
Background: Low plasma high-density lipoprotein cholesterol (HDL-C) levels are a strong, independent, but poorly understood risk factor for cardiovascular disease (CVD). Although this atherogenic lipid abnormality has been widely reported in Australia's Indigenous peoples, Aboriginal and Torres Strait Islanders, the evidence has not come under systematic review. This review therefore examines published data for Indigenous Australians reporting 1) mean $\mathrm{HDL}-\mathrm{C}$ levels for both sexes and 2) factors associated with low HDL-C.
\end{abstract}

Methods: PubMed, Medline and Informit ATSI Health databases were systematically searched between 1950 and 2012 for studies on Indigenous Australians reporting mean HDL-C levels in both sexes. Retrieved studies were evaluated by standard criteria. Low HDL-C was defined as: $<1.0 \mathrm{mmol} / \mathrm{L}$. Analyses of primary data associating measures of HDL-C with other CVD risk factors were also performed.

Results: Fifteen of 93 retrieved studies were identified for inclusion. These provided 58 mean HDL-C levels; 29 for each sex, most obtained in rural/regional (20\%) or remote settings (60\%) and including 51-1641 participants. For Australian Aborigines, mean $\mathrm{HDL}-\mathrm{C}$ values ranged between $0.81-1.50 \mathrm{mmol} / \mathrm{L}$ in females and $0.76-1.60 \mathrm{mmol} / \mathrm{L}$ in males. Two of 15 studies reported HDL-C levels for Torres Strait Islander populations, mean HDL-C: 1.00 or $1.11 \mathrm{mmol} / \mathrm{L}$ for females and 1.01 or $1.13 \mathrm{mmol} / \mathrm{L}$ for males. Low HDL-C was observed only in rural/regional and remote settings - not in national or urban studies $(n=3)$ in either gender. Diabetes prevalence, mean/median waist-to-hip ratio and circulating C-reactive protein levels were negatively associated with HDL-C levels $($ all $P<0.05)$. Thirty-four per cent of studies reported lower mean HDL-C levels in females than in males.

Conclusions: Very low mean HDL-C levels are common in Australian Indigenous populations living in rural and remote communities. Inverse associations between $\mathrm{HDL}-\mathrm{C}$ and central obesity, diabetes prevalence and inflammatory markers suggest a particularly adverse CVD risk factor profile. An absence of sex dichotomy in HDL-C levels warrants further investigation.

Keywords: Indigenous, Australian Aborigines, Torres Strait Islanders, Lipids, Dyslipidaemia, High-density lipoprotein cholesterol, Cardiovascular disease, Cardiovascular disease risk factors, Cardiometabolic, Non-communicable disease

\footnotetext{
* Correspondence: jasmine.lyons@bakeridi.edu.au

${ }^{1}$ Baker IDI Heart and Diabetes Institute, 75 Commercial Road, Melbourne, Victoria 3004, Australia

2Department of Medicine (St. Vincent's), University of Melbourne, Clinical Sciences Building, 29 Regent Street, Fitzroy, Melbourne, Victoria 3065,

Australia

Full list of author information is available at the end of the article
}

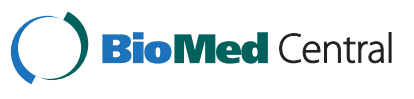

(c) 2014 Lyons et al.; licensee BioMed Central Ltd. This is an Open Access article distributed under the terms of the Creative Commons Attribution License (http://creativecommons.org/licenses/by/4.0), which permits unrestricted use, distribution, and reproduction in any medium, provided the original work is properly credited. The Creative Commons Public Domain Dedication waiver (http://creativecommons.org/publicdomain/zero/1.0/) applies to the data made available in this article, unless otherwise stated. 


\section{Background}

Preventable chronic disease, including cardiovascular disease (CVD) and type 2 diabetes, accounts for $70 \%$ of the difference of burden of disease between Indigenous and broader Australian populations, and is now regarded as one of the greatest causes of current inequities in Indigenous health status [1]. CVD risk factors have been consistently shown to be more pronounced in Indigenous populations and include much higher rates of type 2 diabetes, cigarette smoking, overweight/obesity, alcohol misuse, poor nutrition, depression [2], and the Metabolic Syndrome (MetS), a cluster of various CVD and diabetes risk factors [3,4]. Alongside this burden of preventable non-communicable disease, high rates of infectious disease represent an important cause of morbidity and mortality in Indigenous Australians compared to the broader population [5-10].

One critical aspect of this adverse CVD risk factor profile is the high prevalence of low high-density lipoprotein cholesterol (HDL-C). A low HDL-C level is strongly and inversely associated with risk for coronary heart disease [11]. High HDL-C exerts its cardio-protective effect primarily through its role in reverse cholesterol transport and its anti-inflammatory, anti-thrombotic and antioxidative properties. As endogenous oestrogens have a favorable effect on lipid metabolism, females often have higher HDL-C levels than males [12]. Also, alcohol consumption can increase HDL-C levels. Various metabolic and environmental factors, including the presence of acute or chronic infection, a high intake of refined carbohydrate and cigarette smoking, can decrease HDL-C levels. Importantly, low HDL-C is likely to be a secondary effect from components of the MetS: insulin resistance, central obesity, high triglyceride dyslipidaemia and chronic, low-grade inflammation [13]. To date, no specific clinical targets for HDL-C levels have been determined; thus low HDL-C has been variously defined [14-19]. In Australia, lipid management guidelines from the National Heart Foundation and the Cardiac Society of Australia and New Zealand have set a threshold for low HDL as $<1.0 \mathrm{mmol} / \mathrm{L}$ [17].

Multiple reports describe extremely low HDL-C levels in Australian Indigenous populations [8,9,20-25]. In 1979 very low mean HDL-C levels $(0.85 \mathrm{mmol} / \mathrm{L})$ were reported from a small, rural- Western Australian cohort of young Aboriginal men ( $<35$ years of age) [26] and from a rural community in central Australia, where mean HDL-C levels decreased over an eight year period as obesity and diabetes prevalence increased [22]. Using the same criteria, a recent report determined low HDL$\mathrm{C}$ prevalence in a national Indigenous cohort as $70.2 \%$ [27]. Moreover, low HDL-C is not confined to adults: by the National Cholesterol Education Program Adult Treatment Panel III (NCEP ATP-III) definition of $<40 \mathrm{mg} / \mathrm{dL}$
$(<1.04 \mathrm{mmol} / \mathrm{L})$, low HDL-C was evident in $30 \%$ of Indigenous children/adolescents (9-14 years) from Northern Australia [28]. Crucially, in a 2004 study of 913 participants from Aboriginal communities in central and northern Australia, 95\% of women and $89 \%$ of men were found with low HDL-C $(<1.0 \mathrm{mmol} / \mathrm{L})$ a problem apparent even among those individuals who were lean and without other abnormalities indicative of MetS [29].

Given the consistency in reports of low HDL-C in Australian Indigenous people, we sought to establish whether these findings could be generalized across populations and settings. Our aims were to: 1) collate and summarize published data reporting mean HDL-C levels for both females and males; and 2) where possible, analyze associations between low HDL-C with other CVD clinical risk factors.

\section{Methods}

\section{Definitions}

We use the term 'Indigenous Australians' to refer to individuals identifying as 'Aboriginal' or 'Torres Strait Islander'. Study locations (e.g. remote, urban) were defined as described within each study.

\section{Search strategy}

Using a multi-field search we conducted a search in the PubMed, MEDLINE (Web of Knowledge), and Informit ATSI Health databases. Search terms were:

cholesterol/high density lipoprotein/HDL-C/lipoprotein/dyslipid*/lipid;

Aborigin*/Indigenous/Torres Strait Islander/Oceanic ancestry group;

cardiovascular disease/heart disease/coronary heart disease;

metabolic syndrome/MetS;

Australia.

Truncation of terms captured any variation in terminology. Studies retrieved were restricted to full-article, English-language publications published between January 1950 and January 2012. Additional data sources were obtained by hand search. Narrative reviews, editorials, letters, commentaries and grey literature (to ensure inclusion of only reliable, peer-reviewed data) were excluded. Two investigators (JGL and KZW) conducted the literature searches independently and results were combined.

\section{Study inclusion criteria}

Published original quantitative studies were included for review if they fulfilled the following selection criteria:

1. The study was based solely on Australian Indigenous populations, or provided a separate analysis of Indigenous participants 
2. Standard values (mean, median or geometric mean) of serum or plasma HDL-C levels were reported separately for males and females.

As there is no single standard for low HDL-C, the presentation of mean HDL-C values rather than prevalence rates for low HDL-C were used as an inclusion criterion. We defined low HDL-C as $<1.00 \mathrm{mmol} / \mathrm{L}$, as per Australian clinical guidelines [17]. For all included studies, we required presentation of both male and female values for HDL-C in order to examine gender differences and calculate the female:male HDL-C ratio [12].

\section{Data extraction/study quality assessment}

Summary data for included studies were extracted into a standardized tool that included: citation, study population, year(s) of study, region (national, urban, rural/regional or remote), mean sample age/age range, sample size, response rate, mean HDL-C levels, and method of HDL-C measurement. Where possible, the following outcomes were also extracted as mean values: sex-specific anthropometric measurements (body mass index [BMI], waist circumference $[\mathrm{WC}]$, waist-to-hip ratio [WHR]), age, plasma C-reactive protein (CRP)) plus prevalence rates for diabetes, obesity, current tobacco smoking or infectious disease states. If multiple reports were available for a given study, the most recently published report or the report that provided more comprehensive results was selected for review. The quality of each study was assessed according to study-specific criteria (Table 1), based on previous general recommendations [30]. Each criterion contributed two points to an overall score of 10 . A score of 10 points was considered very high quality; 8-9 high quality; 7-6 moderate quality; and $<5$ low quality. Different surveys reported in a single study [22] were assessed separately. HDL-C data from the 2000 AusDiab study [31] - a national randomized cluster study- provided the non-Indigenous, Australian population reference. To examine possible associations, mean values of various CVD risk factors obtained from study results were plotted as independent variables against mean HDL-C levels, with each sex-specific value aggregated for each analysis between HDL-C and other variables: mean BMI, WC, WHR, age, CRP and prevalence of current smoking and obesity. The degree of association was assessed by Pearson's correlation.

\section{Results}

Overall 93 articles were obtained in the initial literature search while another four were retrieved by hand-search. After evaluation, 15 studies were included for further qualitative and quantitative analysis (Figure 1). Their review was undertaken according to PRISMA guidelines for systematic reviews (see checklist, Additional file 1).

Most included studies were of either high $(41 \%)$ or moderate quality (59\%)- none were of very high or of low quality. All were cross-sectional assessments taken at a single time point, except one [22], where three sequential cross-sectional surveys were undertaken across a single community (1987, 1991 and 1995). Here, because retention rates varied across sex and age group, and cases were not matched across time points; data from each year were extracted and presented separately.

Sample sizes varied in size and location (Table 2), from $\mathrm{n}=51$, (the adult population in a remote community in Western Australia [9]) to $\mathrm{n}=1641$ (23 communities in far north Queensland [32]). Most studies had a strong regional focus; 8 of 15 were conducted in single rural or remote communities in the Northern Territory. One national survey included participants from medical practices in capital cities and from remote communities [33] and two urban surveys were carried out in metropolitan capital cities [34,35]. Six of the 15 studies presented HDL-C data in separate groups according to age, but where a mean overall age was reported, this ranged only between 29.9-40 years, for both males and females. While one study included certain paediatric data [9], data examined here concern only those aged over 15 years.

Women were often overrepresented. Only three studies had fewer females than males: 39\% [9]; 48\% [36]; and $49 \%$ [32], while in all other studies the proportion of females ranged from 54-86\%. Although some study response rates were low (down to 14\%) [34,35], six of 15 studies reported response rates $\geq 80 \%$ [9,23,33,37-39] and one study reported response rates of between 57$97 \%$, depending on survey year [22]. Two studies did not

Table 1 Study quality assessment tool

\begin{tabular}{ll}
\hline Study quality criteria & Example of high score \\
\hline Selection criteria used & Appropriate inclusion/exclusion criteria; low response rates kept to a minimum or possible explanations provided \\
Measurement of study variables & Validated method for lipid measurement; patient self-reports validated against appropriate existing records \\
Design specific sources of bias & Identification and selection of participants limited (e.g. only diabetic patients) \\
Use of appropriate statistics & Primary analysis of effect and control of confounding in analyses \\
Possible sources of bias & Statement of funding sources, conflict of interest \\
\hline
\end{tabular}




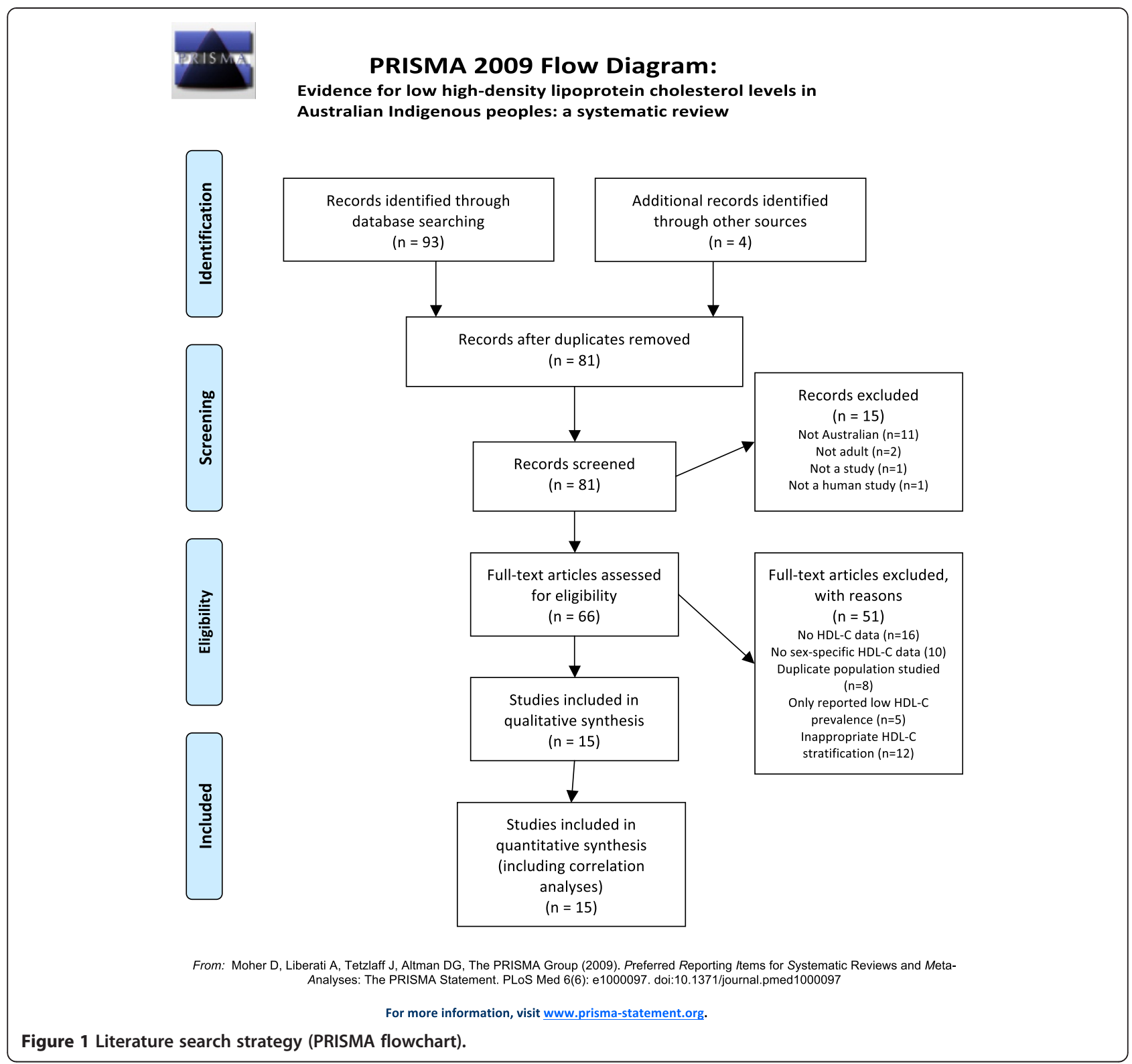

report a response rate $[20,24]$ and in another, data were retrieved from medical records so that a community response rate was not applicable [33]. Another study reported male and female response rates separately; these varied from 53\% (males, 1995) to 96\% (females, 1989) [22]. Included studies were conducted between 1987-2008.

In total, included studies reported 58 sets of HDL-C observations (29 for each gender). Mean HDL-C varied across studies (Figure 2: male [A] and female [B]). The lowest mean HDL-C reported was from a rural community in the Northern Territory, where mean HDL-C was $0.76 \mathrm{mmol} / \mathrm{L}$ in males aged $<35$ years (1991 survey) and $0.81 \mathrm{mmol} / \mathrm{L}$ in females aged 15-24 years (1995 survey) [22]. This contrasts with results from a 1987-88 study in regional Victoria, where the highest mean HDL-C levels were reported: $1.6 \mathrm{mmol} / \mathrm{L}$ in men and $1.5 \mathrm{mmol} / \mathrm{L}$ in women [39]. Indeed, only two studies noted such high mean HDL-C values for men exceeding the mean value from non-Indigenous reference populations of $1.27 \mathrm{mmol} / \mathrm{L} \mathrm{[31]:} 1.60 \mathrm{mmol} / \mathrm{L}$ [39] or $1.38 \mathrm{mmol} / \mathrm{L} \mathrm{[37].}$ In females, no other studies found mean HDL-C values above the non-Indigenous reference $(1.57 \mathrm{mmol} / \mathrm{L}$ [31]). Eleven of fifteen studies did not report whether gender differences in HDL-C levels were of significance. Of the four that made this analysis, two studies found no significant difference $[8,37]$ and one reported significantly lower HDL-C levels in females [20]. The fourth study found Aboriginal women to have significantly higher 
Table 2 Summarized findings of low high-density lipoprotein cholesterol in reviewed studies, grouped by population

\begin{tabular}{|c|c|c|c|c|c|}
\hline \multirow[t]{2}{*}{ Reference } & \multirow[t]{2}{*}{$\begin{array}{l}\text { Year(s) } \\
\text { study } \\
\text { conducted }\end{array}$} & \multirow[t]{2}{*}{ Population, location ${ }^{1}$} & \multirow[t]{2}{*}{ State/territory } & \multicolumn{2}{|c|}{$\begin{array}{l}\text { Low mean } \\
\text { HDL-C }\end{array}$} \\
\hline & & & & Male & Female \\
\hline \multicolumn{6}{|c|}{ Indigenous populations } \\
\hline [33] & 2007-08 & National survey ${ }^{3}$ & NSW, QLD, Central Australia & No & No \\
\hline [35] & 2003-05 & Urban survey from one metropolis ${ }^{4}$ & NT & $\mathrm{No}^{6}$ & No \\
\hline \multicolumn{6}{|c|}{ Australian Aboriginal populations } \\
\hline [37] & 1986 & 1 remote community & NT & No & No \\
\hline [38] & 1987 & 1 remote community & NT & No & No \\
\hline [39] & $1987-88$ & 1 regional community & $\mathrm{VIC}$ & No & No \\
\hline [9] & $\approx 1995$ & 1 remote community, Great Sandy Desert & WA & \multicolumn{2}{|c|}{ Both genders } \\
\hline [23] & 1988 & 1 remote community, homeland residences & NT & \multicolumn{2}{|c|}{ Both genders ${ }^{6}$} \\
\hline \multirow[t]{3}{*}{ [22] } & 1987 & 1 rural community & NT & No & No \\
\hline & 1991 & & & \multicolumn{2}{|c|}{ Both genders ${ }^{7}$} \\
\hline & 1995 & & & \multicolumn{2}{|c|}{ Both genders ${ }^{7}$} \\
\hline [21] & 1996 & 1 remote community & NT & \multicolumn{2}{|c|}{ Both genders } \\
\hline [8] & $1999-2000$ & 1 remote community, East Arnhem Land & NT & No & Yes \\
\hline [36] & 1992-95 & 1 remote community, Tiwi Islands & NT & No & No \\
\hline [20] & 2001-03 & 1 remote community, East Arnhem Land & NT & No & Yes \\
\hline [34] & 2000 & Urban study, one metropolis & WA & No & No \\
\hline [24] & 1993-95 & 11 remote communities, & NT, far-north QLD & $\mathrm{No}^{7}$ & No \\
\hline [32] & 1999-2000 & 23 rural communities & Far-north QLD & $\mathrm{No}^{7}$ & No \\
\hline \multicolumn{6}{|c|}{ Torres Strait Islander populations } \\
\hline [24] & $1993-95$ & 11 remote communities & NT, far-north QLD & $\mathrm{No}^{7}$ & No \\
\hline [32] & $1999-2000$ & 23 rural communities & Far-north QLD & $\mathrm{No}^{7}$ & No \\
\hline
\end{tabular}

Legend:

${ }^{1}$ Ethnicity is reported as defined in the original study.

${ }^{2}$ Low HDL-C defined as mean HDL-C value $<1.00 \mathrm{mmol} / \mathrm{L}$.

${ }^{3} 90 \%$ AA, $9 \%$ TSI, $1 \%$ both AA and TSI.

${ }^{4} 84 \%$ AA; $6 \%$ TSI; $11 \%$ both.

${ }^{6} \mathrm{HDL}-\mathrm{C}$ levels stratified by age: $15-34$ yrs and $>35 \mathrm{yrs}$ of age. In both age groups, results were the same.

${ }^{7} \mathrm{HDL}-\mathrm{C}$ levels stratified by age into: $15-24 \mathrm{yrs}, 25-34 \mathrm{yrs}$ and $>35 \mathrm{yrs}$ of age. For all age groups, results are the same.

Abbreviations: HDL-C high-density lipoprotein cholesterol, AA Aboriginal ethnicity, TSI Torres Strait Islander ethnicity, NSW New South Wales, QLD Queensland,

NT Northern Territory, VIC Victoria, WA Western Australia.

HDL-C than Aboriginal males, although no difference in HDL-C between genders was found among Torres Strait Islanders [24].

While there were no clear gradients in HDL-C according to region, Figure 2 shows that low levels of HDL-C generally predominated in rural and remote-dwelling Indigenous populations. This pattern is confirmed in collated study data (Table 2): all studies reporting low HDL-C in both males and females were conducted in remote or rural areas. This contrasts with the national AusDiab cohort, in which mean HDL-C was not low in either gender. Data from urban metropolitan areas were also consistent; neither the study from Darwin, Northern Territory [35], nor that from Perth, Western Australia [34], showed low mean HDL-C for males or females. Both these studies however, were subject to low response rates: $14 \%$ and 5-20\% (depending on age group), respectively. Only two studies reported HDL-C values specifically for Torres Strait Islander populations, and neither showed low mean HDL-C $[24,32]$.

Laboratory methods of HDL-C measurement are detailed in Additional file 2. The majority of studies report standardized, full or partially automated techniques, whereas HDL-C isolation or precipitation was carried out in only four studies. One study did not state method of HDL-C measurement [36], and in another, varied methods were likely, subject to the practice at each medical service from which medical record data were obtained [33].

Female:male HDL-C ratios are described in Additional file 2. One third of measurements (10 of 29 pairs in total) 


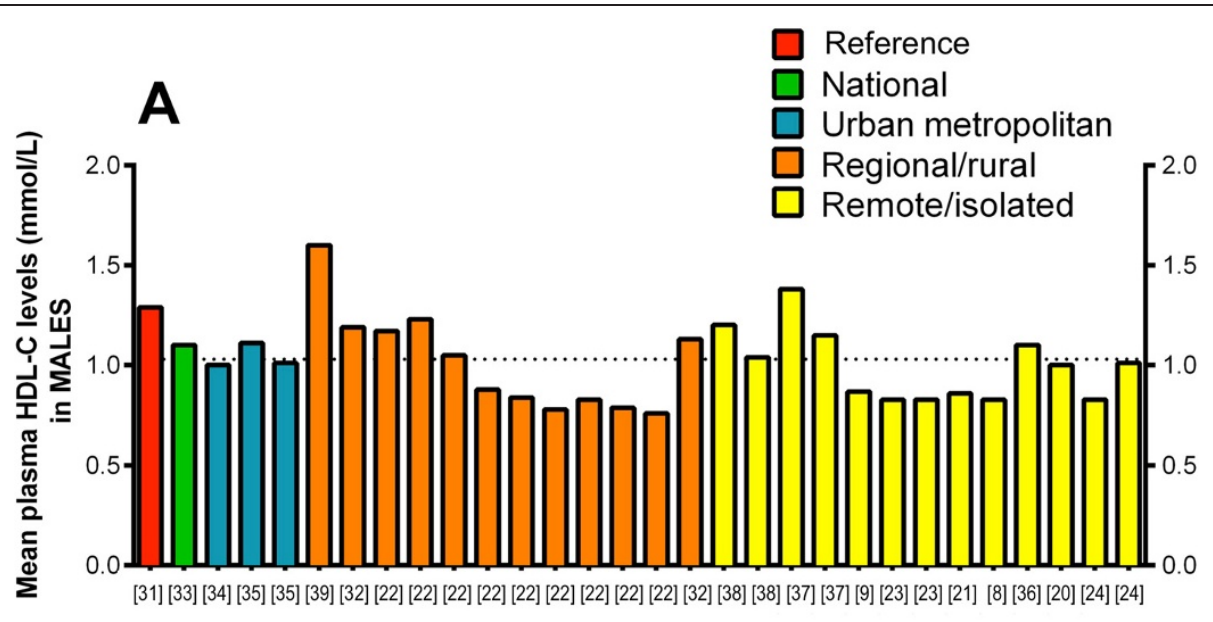

B

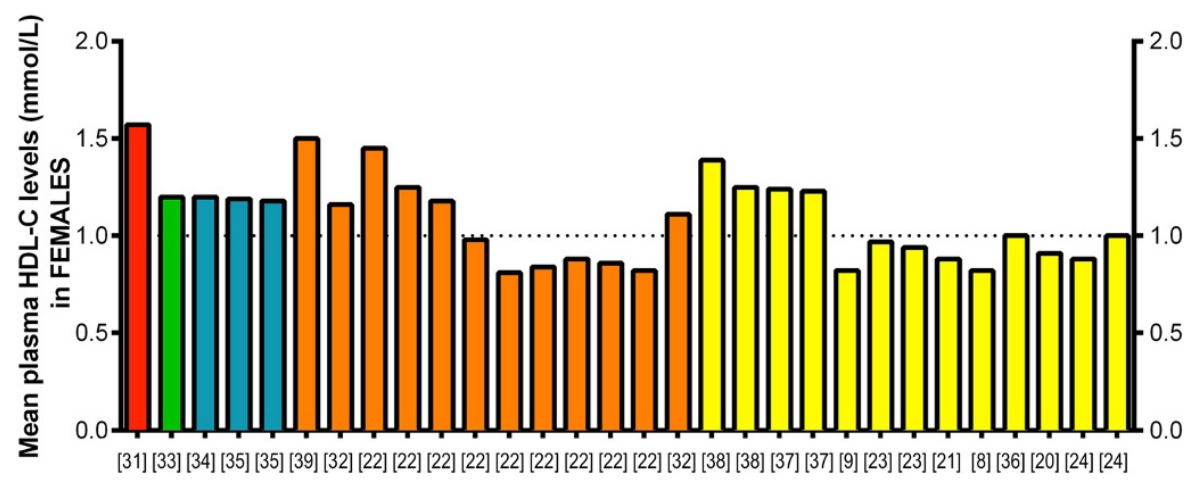

Figure 2 Mean high-density lipoprotein cholesterol (HDL) levels in $[A]$ males and $[B]$ females, according to region. The reference value was taken from a national survey of non-Indigenous Australians [31]. Each bar represents a single measurement; some studies have reported $\geq 2$ values owing to stratification by ethnicity [24,32], age group [22,23,35,37,38] or year of survey [22].

reported lower mean HDL-C levels in females than in males (i.e. ratio $<1.0$ ), which contrasts with the ratio of 1.27 seen in the non-Indigenous reference population [31]. Overall, the lowest female:male ratios observed were in rural/regional and remote settings.

Using data available from included studies, mean HDL-C values were negatively associated with prevalence of diabetes, mean WHR and mean/median plasma levels of CRP (Figure 3). Effect modification by gender was also observed for each of these variables. Diabetes prevalence was significantly inversely associated with HDL-C levels in males $(\mathrm{r}=-.373, \mathrm{P}=0.046)$ but not females $(r=-.314, P=0.1)$. Similarly, CRP levels were significantly associated with HDL-C levels in males $(\mathrm{r}=-.910, \mathrm{P}=$ $0.03)$, but not females $(r=-.728, P=0.16)$ whereas WHR was significantly associated with HDL-C in females $(\mathrm{r}=$ -.428, $\mathrm{P}=0.047)$ but not males $(\mathrm{r}=-.288, \mathrm{P}=0.19)$. Mean $\mathrm{BMI}, \mathrm{WC}$, age and prevalence of current smoking and obesity did not provide evidence of significant relationships with HDL-C levels in either sex-specific or combined correlation analyses (all $\mathrm{P}>0.4$ ).

\section{Discussion}

Our analysis presents collated evidence of low HDL-C as a striking CVD risk factor in Aboriginal and Torres Strait Islander populations. While Indigenous Australians do not constitute a homogeneous group with respect to low HDL-C dyslipidemia, very low HDL-C appears particularly prevalent in rural and remote communities.

Diabetes prevalence is high in Indigenous populations [40]. Thus co-morbidities of diabetes and the MetS are likely to be strongly contributing, if not directly causal, factors in the presentation of low HDL-C. In reports from which we could source data, we found negative associations between mean HDL-C levels and diabetes prevalence, WHR and CRP levels, all well-recognised CVD risk factors in Indigenous communities [8,41-44]. In remote communities, where we found the lowest HDL-C levels, poor nutrition, excessive smoking and a sedentary lifestyle have been well documented. In turn, these factors are known to contribute to elevated plasma levels of the inflammatory marker CRP [45], which we found negatively associated with HDL-C. Although other 


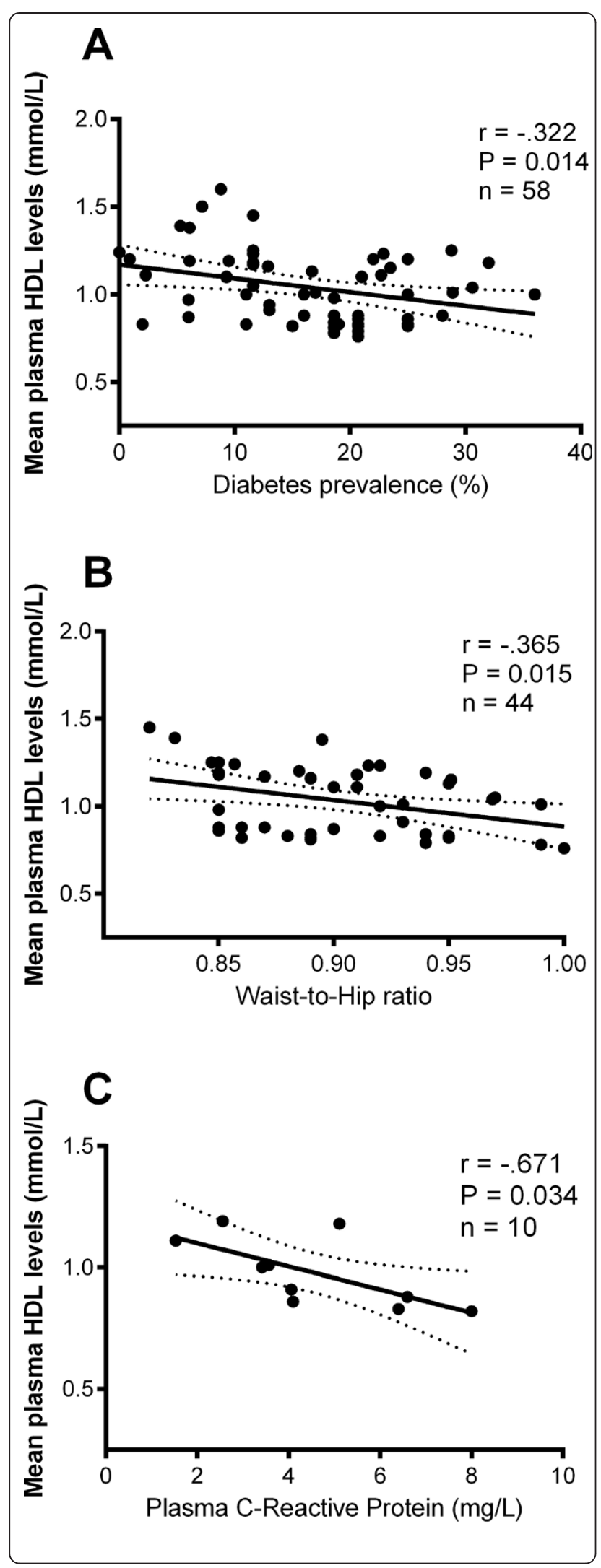

Figure 3 Relationships between mean high-density lipoprotein (HDL) cholesterol levels and selected cardiovascular risk factors: Diabetes prevalence (\%) [A]; Waist-to-hip ratio [B]; Plasma C-Reactive Protein (mg/dL) [C].

risk factors known to be prevalent in Aboriginal populations such as smoking and renal disease [2] were prominent in our included studies they failed to impact on HDL-C in our pooled analyses.

Some populations in rural/regional and remote/isolated locations did not exhibit low HDL-C levels [32,37,38]. Two factors: absence of obesity and high alcohol intake may explain this. One of these studies came from an isolated non-obese community, where mean BMIs were 20.4-23.5 kg/ $\mathrm{m}^{2}$ [37]. Similarly, whereas an initial crosssectional study from a rural community in the Northern Territory, reported high mean HDL-C levels, a subsequent survey 8 years later, indicated both significant weight gain, and a reduction in HDL-C levels [22]. Secondly, alcohol consumption may be critical; a study conducted in a small isolated community in the Northern Territory, found that 'drinking' (defined as those who consumed any alcohol) reduced the risk of low HDL-C (odds ratio: 0.4, 95\% CI 0.2-0.6) [46]. The contribution of alcohol consumption to higher HDL-C in some populations is also suggested by some studies in remote locations [37-39]. In addition in one large study across 23 rural communities, where higher HDL-C levels were evident the prevalence of 'drinking' ranged from 51\%-82\% [32]. Also, Guest et al. acknowledge that alcohol consumption may have influenced the high HDL-C levels seen in another regional population [39].

The preponderance of studies undertaken in rural/remote settings was a prominent finding, typical of broader Indigenous health research [47]. Owing to the sampling method of AusDiab, which excluded districts if they were classified 100\% rural [48], we could not directly compare HDL-C levels between Indigenous and non-Indigenous populations by location. However, in a population survey conducted wholly in non-indigenous rural populations in south-eastern Australia, mean HDL-C levels reported were $1.59 \mathrm{mmol} / \mathrm{L}$ for women and $1.33 \mathrm{mmol} / \mathrm{L}$ for men [49]. These levels are comparable to the AusDiab cohort, and much higher than in Indigenous populations from rural areas included in this review.

Low HDL-C dyslipidaemia clearly results from a complex interplay of environmental and genetic factors [50] with heritability estimated at $40-80 \%$ [51]. Indeed, the Turkish Heart Study found that high prevalence of low HDL-C (70\% of men, $50 \%$ of women) could be attributed to a $25-30 \%$ higher hepatic lipase activity, suggesting a strong genetic component [52]. Few data however are available to link genetic predisposition to low HDL$\mathrm{C}$ levels in Australian Indigenous populations. One early study found that $26 \%$ of a small population from the 
remote Kimberley region of northwestern Australia carried the $\varepsilon 4$ allele for the APOE gene, known to be associated with raised plasma cholesterol and higher risk of CVD [53]. Furthermore, in a medium-sized study ( $\mathrm{n}=$ 155) in southeast Queensland, APOE4 polymorphisms were 1.8 times more prevalent in Indigenous than nonIndigenous participants and associated with high triglycerides and low HDL-C [54]. Thus genetic differences cannot be unequivocally excluded as possible contributors to differing HDL-C phenotype across our study settings, while genetic admixture may contribute to the higher HDL-C observed in urban areas [34,35]. One exception here is a small, early study from northern Western Australia, where urban Aboriginal men had higher HDL-C levels than rural men. As both groups were identified as 'full-blood Aboriginal', factors such as urbanization and higher alcohol consumption may have been critical modifiers of lipid levels [26]. Early life epigenetic modifications may also potentially impact on HDL-C levels [55]. Nevertheless, the body of evidence is clear: non-genetic and modifiable influences appear critically important in the development of low HDL-C dyslipidemia.

Although studies in predominantly North American and western European populations indicate that women have higher HDL-C levels than men, data collated here from rural and remote Indigenous communities indicate this is not necessarily always the case. Different populations display different magnitudes in these sex differences [56]. Other populations of impoverished people (including rural poor in Andhra Pradesh, southern India [57]; Indigenous tribes in Himalayan India [58]), and Indigenous populations undergoing rapid epidemiologic transition in northern Russia, show similar low HDL-C levels in both women and men [59].

As a clinical consequence of a high burden of disease, low HDL-C in the Australian Indigenous population appears intrinsically linked to adverse socio-demographic determinants driving the high rate of poor health (e.g.: education, occupation and income) [60]. Both acute infection and chronic inflammation reduce HDL-C levels [13]. Infection/chronic inflammation are common in Indigenous Australians, particularly those from remote areas, where parasitic, fungal, viral and bacterial infections are promoted by poor household infrastructure, overcrowding and overdue vaccinations [61]. Accordingly, high CRP levels are a common CVD risk factor $[41,44]$. Communicable disease appears to be a potentially important contributor to the highly prevalent low HDL-C and high CRP reported here as evidenced by the negative association we found between mean CRP and mean HDL-C levels. This is consistent with other data $[8,21]$ in Indigenous populations, including inverse associations seen between HDL-C levels and other atherogenic biomarkers such as vascular cell adhesion molecules [21] and fibrinogen $[8,24]$. One small, prospective epidemiological study of critical care patients in central Australia found that despite similar low HDL-C levels upon admission, HDL-C levels only remained low six months after discharge in the Indigenous group (median HDL-C: $0.8 \mathrm{mmol} / \mathrm{L}$ vs. $1.5 \mathrm{mmol} / \mathrm{L}$ in non-indigenous patients) [62]. Also, erythrocyte sedimentation rate, a marker of chronic inflammation, was significantly higher in the Indigenous patients at follow-up. Significantly, proatherogenic changes to HDL-C during states of infection/ inflammation may accelerate CVD risk, beyond the risk conveyed by low HDL-C per se [13].

Our study has some limitations. Due to the small number of often cluster-based studies, external validity with respect to the wider or national Indigenous population in Australia must be uncertain. Nevertheless, we are confident that we give an accurate representation of low HDL-C prevalence in rural and remote communities. One potential source of bias is the variety of methods used to determine HDL-C especially in earlier studies (1980s-90s), although over the last 15 years methodology has been largely consistent. Studies providing only percentage prevalence of low HDL-C at different thresholds were excluded. Although their inclusion would expand the evidence base, it does not aid in finding an estimate of the prevalence of low HDL-C.

Associations about the impact of traditional CVD risk/ 'lifestyle' factors on the presentation of low HDL-C are now well recognized. However, research of lipid-specific metabolic dysfunction is likely to provide further insight into the extent it contributes to CVD risk in such highburden populations. O'Neal et al. [25] identified a particularly atherogenic lipid profile in Aboriginal communities across northern Australia, that was characterized not only by low HDL-C, but also by an increase in small, dense LDL particles known to be highly susceptible to oxidative modification. Dysfunctional changes to lipoprotein composition may also be occurring for HDL as for LDL particles. For example, examination of the role of apolipoprotein-A1, which governs the ability of HDL to perform reverse cholesterol transport, would be valuable in assessing the relative importance of particle number, HDL-C content and function on CVD risk in Australian Indigenous populations. Examination of relationships between HDL-C and infectious disease load in these populations would also be valuable. If confirmed, these features together represent a very high-risk cardio-metabolic profile and may go some part in explaining the excess CVD morbidity and mortality that exists in Indigenous populations.

\section{Conclusions}

This review confirms that low HDL-C levels are common in Australia's Indigenous populations, and predominate in rural and remote locations. Associations found 
between HDL-C levels and other CVD risk factors that are also widespread in these communities provide aggregated evidence linking HDL-C and other features of cardio-metabolic risk, including a relationship between HDL-C and the inflammatory marker CRP. Such interrelationships provide a compelling case in support of comprehensive preventive health programs to reduce the burden of both communicable and non-communicable disease in Indigenous populations.

\section{Additional files}

Additional file 1: PRISMA Guideline checklist.

Additional file 2: Additional characteristics of included review studies, grouped by ethnicity.

\section{Abbreviations}

HDL-C: High density lipoprotein cholesterol; CVD: Cardiovascular disease; CHD: Coronary heart disease; AA: Australian Aborigine; BMI: Body mass index; F: Female; M: Male; MetS: Metabolic syndrome; TSI: Torres Strait Islander; WC: Waist circumference; WHR: Waist-to-hip ratio; CRP: Plasma C-reactive protein; DM: Diabetes mellitus; IGT: Impaired glucose tolerance; PEG: Polyethylene glycol precipitation; CS: Current smokers; OB: Obesity; GM: Geometric mean; NSW: New South Wales; QLD: Queensland; NT: Northern territory; VIC: Victoria; WA: Western Australia.

\section{Competing interests}

The authors declare no competing interests.

\section{Authors' contributions}

KZW conceived of and designed the review. JGL and KZW completed literature search and extracted the data. JGL drafted the manuscript with input from all authors. KZW and KOD revised manuscript critically for important intellectual content. All authors contributed to analysis and interpretation of data and read and approved the final manuscript.

\section{Acknowledgments}

The conduct of this review was supported by the National Health and Medical Research Council (NHMRC; Program Grants 320860 and 631947). JGL is supported by National Heart Foundation of Australia/NHMRC postgraduate scholarship [586739] and the Cardiac Society of Australia and New Zealand. Baker IDI is supported by the Victorian Government's OIS Program.

\section{Author details}

${ }^{1}$ Baker IDI Heart and Diabetes Institute, 75 Commercial Road, Melbourne, Victoria 3004, Australia. 'Department of Medicine (St. Vincent's), University of Melbourne, Clinical Sciences Building, 29 Regent Street, Fitzroy, Melbourne, Victoria 3065, Australia. ${ }^{3}$ School of Population and Global Health, University of Melbourne, 207 Bouverie Street, Melbourne, Victoria 3065, Australia. ${ }^{4}$ School of Population Health, Division of Health Sciences, University of South Australia, North Terrace, Adelaide, South Australia 5000, Australia. ${ }^{5}$ Department of Nutrition and Dietetics, Monash University, 264 Ferntree Gully Road Notting Hill, Victoria 3168 Melbourne, Australia.

Received: 4 March 2014 Accepted: 23 May 2014

Published: 2 June 2014

\section{References}

1. Vos T, Barker B, Begg S, Stanley L, Lopez AD: Burden of disease and injury in Aboriginal and Torres Strait islander peoples: the indigenous health gap. Int J Epidemiol 2009, 38:470-477.

2. Australian Institute of Health and Welfare: The health and welfare of Australia's Aboriginal and Torres Strait Islander people, an overview 2011. In Book The health and welfare of Australia's Aboriginal and Torres Strait Islander people, an overview 2011. City: Australian Institute of Health and Welfare; 2011.
3. Schutte AE, Shemesh T, Rowley K, Best JD, McDermott R, O'Dea K: The metabolic syndrome and changing relationship between blood pressure and insulin with age, as observed in Aboriginal and Torres Strait islander peoples. Diabet Med 2005, 22:1589-1597.

4. Luke JN, Brown A, Daniel M, O'Dea K, Best JD, Jenkins AJ, Wang Z, McDermott RA, Wang Z, Rowley KG: The metabolic syndrome and CVD outcomes for a central Australian cohort. Diabetes Res Clin Pract 2013, 100:e70-e73.

5. Einsiedel L, Fernandes L, Joseph S, Brown A, Woodman RJ: Noncommunicable diseases, infection and survival in a retrospective cohort of indigenous and non-indigenous adults in central Australia. BMJ Open 2013, 3(7):e003070.

6. Maguire GP, Nelson C: Acute rheumatic fever and rheumatic heart disease: an insight into Aboriginal health disadvantage and remote Australia. Med J Aust 2006, 184:506.

7. Maguire GP, Arthur AD, Boustead PJ, Dwyer B, Currie BJ: Clinical experience and outcomes of community-acquired and nosocomial methicillin-resistant Staphylococcus aureus in a northern Australian hospital. J Hosp Infect 1998, 38:273-281.

8. McDonald S, Maguire G, Duarte N, Wang XL, Hoy W: C-reactive protein, cardiovascular risk, and renal disease in a remote Australian Aboriginal community. Clin Sci (Lond) 2004, 106:121-128.

9. Gracey M, Spargo RM, Smith P, Smith RM, Burke V, Beilin LJ, Beilby J, Chin C: Risk factors for ill-health in a remote desert-dwelling aboriginal community in Western Australia. Aust NZ J Med 1996, 26:171-179.

10. Einsiedel LJ, Woodman RJ: Two nations: racial disparities in bloodstream infections recorded at Alice Springs Hospital, central Australia, 2001-2005. Med J Aust 2010, 192:567-571.

11. Chirovsky DR, Fedirko V, Cui Y, Sazonov V, Barter P: Prospective studies on the relationship between high-density lipoprotein cholesterol and cardiovascular risk: a systematic review. Eur J Cardiovasc Prev Rehabil 2009, 16:404-423.

12. Barton M: Cholesterol and atherosclerosis: modulation by oestrogen. Curr Opin Lipidol 2013, 24:214-220.

13. Kontush A, Chapman MJ: Functionally defective high-density lipoprotein: a new therapeutic target at the crossroads of dyslipidemia, inflammation, and atherosclerosis. Pharmacol Rev 2006, 58:342-374.

14. Expert Panel on Detection, Evaluation, and Treatment of High Blood Cholesterol in Adults: Executive Summary of the third report of the National Cholesterol Education Program (NCEP) expert panel on detection, evaluation, and treatment of high blood cholesterol in adults (Adult Treatment Panel III). JAMA 2001, 285:2486-2497.

15. Alberti KG, Zimmet $P$, Shaw J: Metabolic syndrome-a new world-wide definition. A consensus statement from the International Diabetes Federation. Diabet Med 2006, 23:469-480.

16. Chapman MJ, Ginsberg HN, Amarenco P, Andreotti F, Boren J, Catapano AL, Descamps OS, Fisher E, Kovanen PT, Kuivenhoven JA, Lesnik P, Masana L, Nordestgaard BG, Ray KK, Reiner Z, Taskinen MR, Tokgozoglu L, TybjaergHansen A, Watts GF, European Atherosclerosis Society Consensus Panel: Triglyceride-rich lipoproteins and high-density lipoprotein cholesterol in patients at high risk of cardiovascular disease: evidence and guidance for management. Eur Heart J 2011, 32:1345-1361.

17. Tonkin A, Barter P, Best J, Boyden A, Furler J, Hossack K, Sullivan D, Thompson P, Vale M, Cooper C, Robinson M, Clune E, National Heart Foundation of Australia, Cardiac Society of Australia and New Zealand: National Heart Foundation of Australia and the Cardiac Society of Australia and New Zealand: position statement on lipid management-2005. Heart Lung Circ 2005, 14:275-291.

18. Wyszynski DF, Waterworth DM, Barter PJ, Cohen J, Kesaniemi YA, Mahley RW, McPherson R, Waeber G, Bersot TP, Sharma SS, Nolan V, Middleton LT, Sundseth SS, Farrer LA, Mooser V, Grundy SM: Relation between atherogenic dyslipidemia and the Adult Treatment Program-III definition of metabolic syndrome (Genetic Epidemiology of Metabolic Syndrome Project). Am J Cardiol 2005, 95:194-198.

19. Graham I, Atar D, Borch-Johnsen K, Boysen G, Burell G, Cifkova R, Dallongeville J, De Backer G, Ebrahim S, Gjelsvik B, Herrmann-Lingen C, Hoes A, Humphries S, Knapton M, Perk J, Priori SG, Pyorala K, Reiner Z, Ruilope L, Sans-Menendez S, Op Reimer WS, Weissberg P, Wood D, Yarnell J, Zamorano JL, Walma E, Fitzgerald T, Cooney MT, Dudina A, Vahanian A, et al: European guidelines on cardiovascular disease prevention in clinical practice: full text. Fourth Joint Task Force of the European Society of Cardiology and 
other societies on cardiovascular disease prevention in clinical practice (constituted by representatives of nine societies and by invited experts). Eur Heart J 2007, 28:2375-2414.

20. Shemesh T, Rowley KG, Jenkins A, Brimblecombe J, Best JD, O'Dea K Differential association of C-reactive protein with adiposity in men and women in an Aboriginal community in northeast Arnhem Land of Australia. Int J Obes (Lond) 2007, 31:103-108.

21. Rowley K, Walker KZ, Cohen J, Jenkins AJ, O'Neal D, Su Q, Best JD, O'Dea K: Inflammation and vascular endothelial activation in an Aboriginal population: relationships to coronary disease risk factors and nutritional markers. Med J Aust 2003, 178:495-500.

22. McDermott R, Rowley KG, Lee AJ, Knight S, O'Dea K: Increase in prevalence of obesity and diabetes and decrease in plasma cholesterol in a central Australian aboriginal community. Med J Aust 2000, 172:480-484.

23. Gault A, O'Dea K, Rowley KG, McLeay T, Traianedes K: Abnormal glucose tolerance and other coronary heart disease risk factors in an isolated aboriginal community in central Australia. Diabetes Care 1996, 19:1269-1273

24. Wang Z, Rowley K, Best J, McDermott R, Taylor M, O'Dea K: Hemostatic factors in Australian Aboriginal and Torres Strait islander populations. Metab Clin Exp 2007, 56:629-635.

25. O'Neal DN, Piers LS, Iser DM, Rowley KG, Jenkins AJ, Best JD, O'Dea K: Australian Aboriginal people and Torres Strait islanders have an atherogenic lipid profile that is characterised by low HDL-cholesterol level and small LDL particles. Atherosclerosis 2008, 201:368-377.

26. O'Dea K, Spargo RM, Nestel PJ: Impact of Westernization on carbohydrate and lipid metabolism in Australian Aborigines. Diabetologia 1982, 22:148-153.

27. Luke JN, Brown AD, Brazionis L, O'Dea K, Best JD, McDermott RA, Wang Z, Wang Z, Rowley KG: Exploring clinical predictors of cardiovascular disease in a central Australian Aboriginal cohort. Eur J Prev Cardiol 2013, 20:246-253.

28. Sellers EA, Singh GR, Sayers SM: Large waist but low body mass index: the metabolic syndrome in Australian Aboriginal children. J Pediatr 2008, 153:222-227.

29. Shemesh T, Rowley KG, Piers LS, Best JD, O'Dea K: Low high-density lipoprotein-cholesterol is the most prevalent metabolic abnormality for Australian Aboriginal men and women even when lean. Eur J Cardiovasc Prev Rehabil 2008, 15:49-51

30. Sanderson S, Tatt ID, Higgins JP: Tools for assessing quality and susceptibility to bias in observational studies in epidemiology: a systematic review and annotated bibliography. Int J Epidemiol 2007, 36:666-676.

31. Snijder MB, Zimmet PZ, Visser M, Dekker JM, Seidell JC, Shaw JE: Independent and opposite associations of waist and hip circumferences with diabetes, hypertension and dyslipidemia: the AusDiab Study. Int J Obes Relat Metab Disord 2004, 28:402-409.

32. Li M, McDermott RA: Using anthropometric indices to predict cardio-metabolic risk factors in Australian indigenous populations. Diabetes Res Clin Pract 2010, 87:401-406.

33. Peiris DP, Patel AA, Cass A, Howard MP, Tchan ML, Brady JP, De Vries J, Rickards BA, Yarnold DJ, Hayman NE, Brown AD: Cardiovascular disease risk management for Aboriginal and Torres Strait Islander peoples in primary health care settings: findings from the Kanyini Audit. Med J Aust 2009, 191:304-309.

34. Bradshaw PJ, Wilkes ET, Thompson PL: Determinants of carotid intima-medial thickness in an urban Australian Aboriginal population. Atherosclerosis 2007, 192:218-223.

35. O'Dea K, Cunningham J, Maple-Brown L, Weeramanthri T, Shaw J, Dunbar T, Zimmet P: Diabetes and cardiovascular risk factors in urban indigenous adults: results from the DRUID study. Diabetes Res Clin Pract 2008, 80:483-489.

36. Wang Z, Hoy WE: Is the Framingham coronary heart disease absolute risk function applicable to Aboriginal people? Med J Aust 2005, 182:66-69.

37. O'Dea K, Lion RJ, Lee A, Traianedes K, Hopper JL, Rae C: Diabetes, hyperinsulinemia, and hyperlipidemia in small aboriginal community in northern Australia. Diabetes Care 1990, 13:830-835

38. O'Dea K, Patel M, Kubisch D, Hopper J, Traianedes K: Obesity, diabetes, and hyperlipidemia in a central Australian aboriginal community with a long history of acculturation. Diabetes Care 1993, 16:1004-1010.
39. Guest CS, O'Dea K, Larkins RG: Blood pressure, lipids and other risk factors for cardiovascular disease in Aborigines and persons of European descent of southeastern Australia. Aust J Public Health 1994, 18:79-86.

40. Minges KE, Zimmet P, Magliano DJ, Dunstan DW, Brown A, Shaw JE: Diabetes prevalence and determinants in Indigenous Australian populations: a systematic review. Diabetes Res Clin Pract 2011, 93:139-149.

41. Shemesh T, Rowley KG, Jenkins AJ, Best JD, O'Dea K: C-reactive protein concentrations are very high and more stable over time than the traditional vascular risk factors total cholesterol and systolic blood pressure in an Australian aboriginal cohort. Clin Chem 2009, 55:336-341.

42. Maple-Brown $\sqcup$, Cunningham J, Nandi N, Hodge A, O'Dea K: Fibrinogen and associated risk factors in a high-risk population: urban indigenous Australians, the DRUID Study. Cardiovasc Diabetol 2010, 9:69.

43. Maple-Brown L, Brimblecombe J, Connelly PW, Harris SB, Mamakeesick M, Zinman B, O'Dea K, Hanley AJ: Similarities and differences in cardiometabolic risk factors among remote Aboriginal Australian and Canadian cohorts. Diabetes Res Clin Pract 2013, 100:133-141.

44. Hodge AM, Maple-Brown L, Cunningham J, Boyle J, Dunbar T, Weeramanthri T, Shaw J, O'Dea K: Abdominal obesity and other risk factors largely explain the high CRP in indigenous Australians relative to the general population, but not gender differences: a cross-sectional study. BMC Public Health 2010, 10:700.

45. Kao PC, Shiesh SC, Wu TJ: Serum C-reactive protein as a marker for wellness assessment. Ann Clin Lab Sci 2006, 36:163-169.

46. Hoy WE, Norman RJ, Hayhurst BG, Pugsley DJ: A health profile of adults in a Northern territory aboriginal community, with an emphasis on preventable morbidities. Aust N Z J Public Health 1997, 21:121-126.

47. Eades SJ, Taylor B, Bailey S, Williamson AB, Craig JC, Redman S, Investigators S: The health of urban Aboriginal people: insufficient data to close the gap. Med J Aust 2010, 193:521-524.

48. Dunstan DW, Zimmet PZ, Welborn TA, Cameron AJ, Shaw J, de Courten M, Jolley D, McCarty DJ, Australian Diabetes O, Lifestyle S: The Australian diabetes, obesity and lifestyle study (AusDiab)-methods and response rates. Diabetes Res Clin Pract 2002, 57:119-129.

49. Janus ED, Tideman PA, Dunbar JA, Kilkkinen A, Bunker SJ, Philpot B, Tirimacco R, Mc Namara K, Heistaro S, Laatikainen T: Dyslipidaemia in rural Australia: prevalence, awareness, and adherence to treatment guidelines in the greater green triangle risk factor study. Med J Aust 2010, 192:127-132.

50. Peloso GM, Demissie S, Collins D, Mirel DB, Gabriel SB, Cupples LA, Robins SJ, Schaefer EJ, Brousseau ME: Common genetic variation in multiple metabolic pathways influences susceptibility to low HDL-cholesterol and coronary heart disease. J Lipid Res 2010, 51:3524-3532.

51. Boes E, Coassin S, Kollerits B, Heid IM, Kronenberg F: Geneticepidemiological evidence on genes associated with HDL cholesterol levels: a systematic in-depth review. Exp Gerontol 2009, 44:136-160.

52. Mahley RW, Pepin J, Palaoglu KE, Malloy MJ, Kane JP, Bersot TP: Low levels of high density lipoproteins in Turks, a population with elevated hepatic lipase. High density lipoprotein characterization and gender-specific effects of apolipoprotein e genotype. J Lipid Res 2000, 41:1290-1301.

53. Kamboh MI, Harmony JA, Sepehrnia B, Nwankwo M, Ferrell RE: Genetic studies of human apolipoproteins. XX. Genetic polymorphism of apolipoprotein $\mathrm{J}$ and its impact on quantitative lipid traits in normolipidemic subjects. Am J Hum Genet 1991, 49:1167-1173.

54. Shaw JT, Tate J, Kesting JB, Marczak M, Berkholz JR, Lovelock PK, Purdie D, Hickman P, Cameron DP: Apolipoprotein E polymorphism in indigenous Australians: allelic frequencies and relationship with dyslipidaemia. Med J Aust 1999, 170:161-164.

55. McNamara BJ, Gubhaju L, Chamberlain C, Stanley F, Eades SJ: Early life influences on cardio-metabolic disease risk in aboriginal populations-what is the evidence? A systematic review of longitudinal and case-control studies. Int J Epidemiol 2012, 41:1661-1682.

56. Chandalia M, Mohan V, Adams-Huet B, Deepa R, Abate N: Ethnic difference in sex gap in high-density lipoprotein cholesterol between Asian Indians and Whites. J Investig Med 2008, 56:574-580.

57. Chow C, Cardona M, Raju PK, lyengar S, Sukumar A, Raju R, Colman S, Madhav P, Raju R, Reddy KS, Celermajer D, Neal B: Cardiovascular disease and risk factors among 345 adults in rural India-the Andhra Pradesh rural health initiative. Int J Cardiol 2007, 116:180-185.

58. Sarkar S, Das M, Mukhopadhyay B, Chakrabarti C, Majumder PP: High prevalence of metabolic syndrome \& its correlates in two tribal 
populations of India \& the impact of urbanization. Indian J Med Res 2006, 123:679-686.

59. Rode A, Shephard RJ: Modernization of lifestyle, body fat content and body fat distribution: a comparison of Igloolik Inuit and Volochanka nGanasan. Int J Obes Relat Metab Disord 1995, 19:709-716.

60. Brown A, Carrington MJ, McGrady M, Lee G, Zeitz C, Krum H, Rowley K Stewart S: Cardiometabolic risk and disease in Indigenous Australians: the heart of the heart study. Int I Cardiol 2014, 171:377-383.

61. McDonald E, Bailie R, Brewster D, Morris P: Are hygiene and public health interventions likely to improve outcomes for Australian Aboriginal children living in remote communities? A systematic review of the literature. BMC Public Health 2008, 8:153.

62. Secombe PJ, Brown A, Kruger PS, Stewart PC: Lipid profiles and persisting inflammation following critical illness in a central Australian population: a prospective longitudinal observational study. Intern Med J 2013, 43:445-449.

doi:10.1186/1471-2458-14-545

Cite this article as: Lyons et al:: Evidence for low high-density

lipoprotein cholesterol levels in Australian indigenous peoples: a systematic review. BMC Public Health 2014 14:545.

\section{Submit your next manuscript to BioMed Central and take full advantage of:}

- Convenient online submission

- Thorough peer review

- No space constraints or color figure charges

- Immediate publication on acceptance

- Inclusion in PubMed, CAS, Scopus and Google Scholar

- Research which is freely available for redistribution 